\title{
Ensiklopedia Digital Interaktif Songket Palembang Berbasis Mobile Device untuk Siswa Jenjang SMP
}

\author{
Intan Permata Saria1, Fahmi Candra Permana ${ }^{\mathrm{a} 2}$, Feri Hidayatullah Firmansyah ${ }^{\mathrm{a} 3}$ \\ aUniversitas Pendidikan Indonesia, Fakultas Kampus Cibiru \\ Bandung, Indonesia \\ 1 Intanpermatasari@upi.edu \\ 2Fahmicandrap@gmail.com \\ 3Feri.firmansyah@upi.edu
}

\begin{abstract}
Abstrak
Songket Palembang merupakan salah satu wastra Indonesia yang kaya akan keanekaragaman hiasnya. Songket Palembang tidak hanya memiliki makna estetis, ada kandungan nilai filosofis dan makna yang sangat dalam untuk setiap helai kain songket, terutama pada songket yang diproduksi diawal-awal kemunculannya. Seiring dengan perkembangan songket tersebut, saat ini terdapat beberapa songket yang tidak memenuhi aturan dalam struktur motifnya, sehingga sulit membedakan motif-motif songket. Apabila hal ini dibiarkan saja, maka lama kelamaan satu per satu nilai dan makna dari wastra Indonesia akan hilang beriringan dengan deras arus globalisasi saat ini. Selain itu, bayaknya ragam hias yang dimiliki songket Palembang namun tidak diiringi dengan minat generasi muda untuk mengetahui ragam hias tradisional. Dalam rangka memperkuat identitas bangsa, perlunya upaya dan tindakan untuk melindungi dan melestarikan budaya Indonesia kepada generasi muda, terutama pada remaja. Penelitian ini menggunakan pendekatan metode Design and Development Research (D\&D). Perancangan aplikasi diadaptasikan berdasarkan karakteristik remaja, sehingga remaja dapat lebih tertarik untuk mengenal dan mulai menyukai kain tradisional. Dengan adanya ensiklopedia digital interaktif ragam hias songket Palembang ini siswa dapat lebih memotivasi siswa dalam mengenal konten tradisional Indonesia.
\end{abstract}

Kata kunci: Ensiklopedia Digital, Media Interaktif, Songket Palembang, Mobile Device

Abstract

Songket Palembang is one of Indonesian literature which is rich in ornamental diversity. Songket Palembang does not only have an aesthetic meaning, there is a very deep philosophical value and meaning for each piece of songket cloth, especially in songket that was produced in the early days of its appearance. Along with the development of the songket, currently there are some songket that do not meet the rules in the structure of the motif, so it is difficult to distinguish the songket motifs. If this is allowed to do so, over time the values and meanings of Indonesian literature will disappear along with the current swift flow of globalization. In addition, there are many kinds of decorations that Palembang songket has, but it is not accompanied by the interest of the younger generation to know traditional decorations. In order to strengthen national identity, efforts and actions are needed to protect and preserve Indonesian culture for the younger generation, especially adolescents. This study used the Design and Development Research (D\&D) method approach. The application design is adapted based on the characteristics of adolescents, so that teenagers can be more interested in getting to know and starting to like traditional fabrics. With the interactive digital encyclopedia of Palembang songket decorations, students can further motivate students to get to know traditional Indonesian content.

Keywords: Digital Encyclopedia, Interactive Media, Songket Palembang, Mobile Device 


\section{Pendahuluan}

Songket Palembang merupakan salah satu jenis tekstil tenun terbaik di dunia [1]. Songket Palembang memiliki kekhasan tersendiri pada benang emas, kehalusan, dan keindahan pada ragam hias motifnya. Data Balitbangovda Sumsel menyebutkan sudah tercatat 74 motif songket Palembang (Ernilarizar, 2015) [2]. Songket Palembang memiliki makna estetis, nilai filosofis dan makna yang sangat mendalam pada setiap helai kain ragam hias motif songket, terutama pada motif songket lama [3]. Berdasarkan fakta yang ada, Pengrajin dan pengusaha songket lebih mengutamakan minat konsumen sehingga muncul motif-motif tengah yang tidak lagi memiliki nilai filosofis dan makna, serta ada beberapa motif songket Palembang tidak memenuhi aturan dalam struktur kainnya. Pakar kain songket Palembang Anna Komari (2013) menjelaskan dalam wawancara bahwa kurangnya minat generasi muda terhadap kain tradisional songket saat ini. Apabila hal ini terus menerus dilakukan, maka lama kelamaan nilai dan makna dari kain tradisional Indonesia akan hilang beriringan dengan deras arus globalisasi.

Perlunya upaya untuk memperkuat identitas bangsa dan melestarikan wastra budaya Indonesia. Remaja sebagai generasi penerus bangsa memiliki peran besar dalam menjaga kelestarian budaya dan penyampai informasi dari generasi ke generasi, dengan karakteristik remaja saat ini, yaitu teknologi digital menjadi gaya hidupnya, menyukai informasi visual, serta tertarik pada informasi dalam bentuk multimedia interaktif. Adanya Teknologi Multimedia dan digital interaktif dapat memberikan solusi dalam pengembangan media edukasi. Interaktif merupakan hubungan komunikasi dua arah antara manusia (user) dan produk multimedia (aplikasi) [4]. Penelitian Lindstrom (1994) menunjukkan bahwa orang mengingat 20\% dari apa yang mereka lihat, $40 \%$ dari apa mereka lihat dan dengar, dan sekitar $75 \%$ dari apa yang mereka lihat dan dengar dan lakukan secara bersamaan [5].

Mobile device merupakan salah satu perangkat yang menarik karena penggunaannya yang relatif lebih mudah dan praktis dibandingkan komputer/laptop dengan penggunaan tenaga dan waktu yang sedikit. Hasil survey Kominfo pada tahun 2017 menunjukkan bahwa lebih dari setengah masyarakat Indonesia sudah memiliki smartphone (66,31\%). Survey berikutnya menunjukkan $65,34 \%$ pengguna smartphone adalah anak usia 9-19 tahun dan 59,89\% terdiri dari siswa SMP [6]. Hasil survey ini menyimpulkan bahwa remaja telah banyak menggunakan mobile device.

Ensiklopedia digital merupakan sebuah kamus yang menghimpun informasi secara teratur, memberikan penjelasan lebih mendalam dan lebih sering dilengkapi dengan informasi visual [7]. ensiklopedia digital interaktif berbasis mobile device dapat menjadi salah satu cara untuk mengenalkan, menjaga, dan melestarikan kain tradisional Indonesia, agar generasi muda termotivasi untuk mengetahuinya. Interaksi desain harus menumbuhkan pendekatan untuk pendidikan [8]. Hal ini juga dapat dikaitkan pada UUD Negara Republik Indonesia tahun 1945, pasal 31 dan 32 yang menyatakan bahwa Pendidikan dan kebudayaan adalah dua unsur yang saling mendukung satu sama lain. Bila pendidikan maju, maka kebudayaan juga akan maju.

Ensiklopedia digital interaktif peneliti pilih dikarenakan sudah pernah dilakukan sebelumnya sebagai media penyampaian informasi budaya lokal. Adapun beberapa penelitian terdahulu yang berkaitan dengan Media digital interaktif sebagai media penyampaian informasi budaya, yaitu Bima, N., (2013) merancang Ensiklopedia Digital Interaktif Tokoh Wayang Kulit Cirebon Pada Mobile Device [7] dan J. A. Abubakar, (2016) media digital interaktif pada pembelajaran warisan arsitektur [9]. Semakin berkembangnya Media Digital Interaktif dengan konten budaya, sehingga peneliti bertujuan untuk mengembangkan Ensiklopedia digital interaktif sebagai media penyampaian informasi budaya lokal kain tradisional Indonesia.

Berdasarkan fakta dan permasalahan yang ada, peneliti bertujuan membuat Ensiklopedia Digital Interaktif Ragam Hias Songket Palembang Berbasis Mobile device sebagai Media Edukasi Pengenalan wastra Indonesia untuk Siswa Jenjang SMP. Aplikasi ensiklopedia digital interaktif ini dirancang berdasarkan karakteristik remaja, yaitu informasi dikemas dalam bentuk informasi visual dengan pengembangan fitur mini game dan kuis, Sehingga informasi songket Palembang yang awalnya terkesan kuno dan membosankan, menjadi informasi yang lebih 
sederhana, interaktif, menarik, dan mudah dipahami. Aplikasi ini menggunakan format ensiklopedia berbasis mobile device; Smartphone atau tablet dan unity sebagai tools utama perancangan aplikasi dengan menggunakan bahasa pemrograman C\#. Ensiklopedia ini bertujuan sebagai pengetahuan dasar informasi ragam hias songket Palembang agar remaja dapat lebih tertarik untuk mengenal dan mencintai kain tradisional dalam negeri, sehingga nilai budayanya tidak hilang dan dapat diwariskan kepada generasi penerus tanpa berkurang nilainya.

\section{Metode Penelitian}

Penelitian ini menggunakan Metode pendekatan Design and Development Research (D\&D). D\&D research terdiri dari dua karakteristik, yaitu: menghasilkan produk (artefak) dan produk yang dihasilkan melalui proses penelitian. Desain Penelitian yang digunakan merujuk dari enam tahap $D \& D$ Reseach [10]. Tahapan-tahapan metode penelitian dapat di ilustrasikan melalui bagan sebagai berikut.

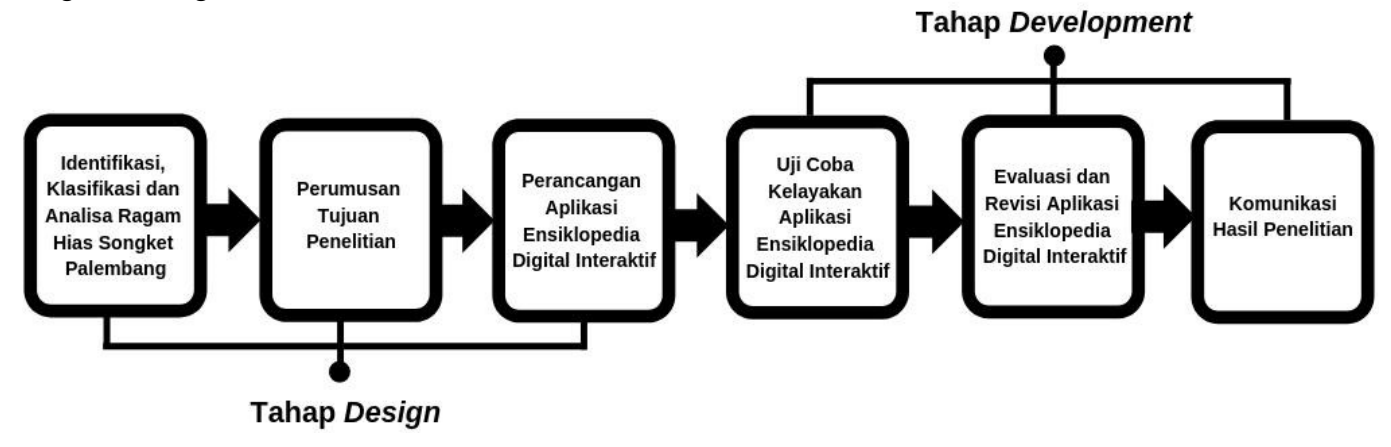

Gambar 1. Tahapan Metode D\&D Reseach

Adapun uraian dari Alur Metode D\&D Reseach sebagai berikut.

a. Identifikasi, Klasifikasi, dan Analisa songketPalembang sebagai konten pada aplikasi.

b. Perumusan tujuan penelitian, yaitu bagaimana rancangan ensiklopedia digital interaktif yang tepat untuk memperkenalkan ragam hias songket Palembang pada siswa SMP menggunakan mobile device.

c. Rancangan aset grafis dan pembuatan endisiklopedia digital interaktif berdasarkan karakteristik remaja yang di fokuskan pada siswa jenjang SMP sebagai target pengguna.

d. Uji kelayakan aplikasi yang diujicobakan pada siswa SMP Labschool UPI Cibiru. untuk mendapatkan feedback dari pengguna.

e. Evaluasii dan revisi aplikasi yang telah di uji cobakan.

f. Mengomunikasikan hasil evaluasi dan revisi yang menjadi hasil akhir penelitian melalui seminar dan jurnal nasional.

Lokasi penelitian ditentukan di di SMP Labschool UPI Cibiru Provinsi Jawa Barat. Sampel subyek penelitian dilakukan secara Stratified Random Sampling. Subyek penelitian terdiri dari Siswa-siswi SMP. Teknik Pengumpulan data menggunakan wawancara, observasi, dokumentasi dan angket. Analis data menggunakan teknik anisis kuanlitatif deskriptif dengan pengukuran Skala Likert. Adapun Tahap Perancangan Aplikasi dilakukan dalam 3 Tahap sebagai berikut.

1) Tahap Perumusan konsep desain aplikasi: melakukan mind-mapping dan pembuatan sketsa keseluruhan dari aplikasi (Wireframe). Tahap perumusan konsep komunikasi, konsep media dan konsep desain, serta bagaimana aplikasi dapat dijalankan dan dioperasikan.

2) Tahap Desain: Pembuatan konten \& aset grafis: dalam tahap ini dilakukan penyediaan semua aset grafis dari aplikasi yang dirancang berdasarkan hasil analisis data sebelumnya. Peneliti juga melakukan pengolahan foto ke dalam bentuk grafis 2D dan proses digital painting grafis agar terlihat lebih menarik.

3) Tahap programming: Setelah aset grafis dibuat, tahap selanjutnya adalah proses pembuatan aplikasi menggunakan software unity. Dalam tahap ini Programmer membuat aplikasi, memasukkan aset grafis dan konten yang telah dibuat kedalam program unity. 
Kemudian penerapan aset grafis yang telah dirancang menuju ke perintah-perintah operasional/ programming pada perangkat mobile.

\section{Hasil dan Pembahasan}

Adapun hasil yang telah tercapai dari penelitian ini adalah sebuah aplikasi ensiklopedia digital interaktif untuk mengenalkan keanekaragaman hias songket Palembang dengan memanfaatkan mobile device sebagai berikut.

\subsection{Konspe Umum}

Pemetaan Konten Aplikasi/Mapping

Pemetaan atau mapping keseluruhan isi dari aplikasi ensiklopedi digital interaktif songket Palembang disusun seperti pada gambar 2 berikut.

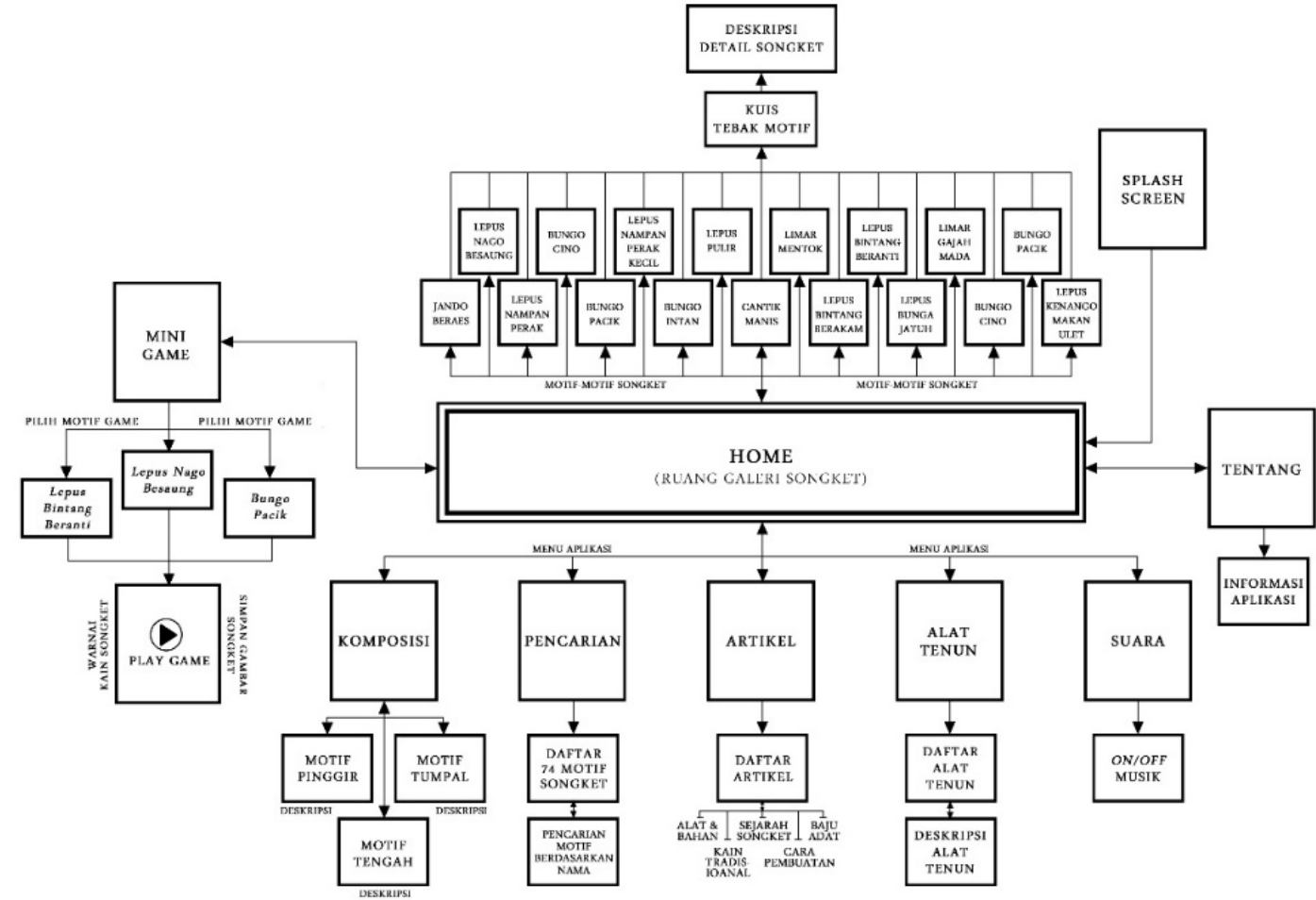

Gambar 2. Mapping Aplikasi Ensiklopedia Digital Interaktif Songket Palembang

\subsection{Konsep Komunikasi}

Pengemasan informasi pada aplikasi merujuk pada hasil analisis media yang telah dilakukan, yang disesuaikan dengan karakterstik pengguna (siswa SMP). Konsep yang digunakan adalah konsep interaktif, mini game dan kuis sederhana dengan menggabungkan komponen multimedia seperti: teks, ilustrasi 2 dimensi, efek animasi, musik tradisional, dan sound effect, serta Aplikasi dalam bentuk offline. Peneliti menggunakan konsep kemudahan, kejelasan, dan kesederhanaan pada aplikasi sebagai poin utama dalam penyajian informasi. Perancangan aplikasi lebih banyak menggunakan visual grafis dan menyederhanakan infomasi dalam bentuk teks. Tujuannya agar pengguna lebih tertarik untuk mengetahui informasi lebih dalam dan mempermudah dalam menerima informasi dengan tidak lupa mengedepankan informasi yang lengkap dan penjelasan lebih mendalam.

\subsection{Konsep Visual}

Pada aplikasi ini terdapat konsep visual yang menjadi elemen penting dalam merancang Desain latar/setting galeri songket, yaitu menggunakan konsep interior classic, glamour, dan tidak meninggalkan unsur-unsur tradisional yang beradaptasi dari gaya visual rumah adat tradisional kota Palembang, yaitu rumah limas. Desain setting/latar galeri menjadi acuan untuk mendesain elemen-elemen lain pada aplikasi ini. 


\section{Warna}

Warna yang digunakan dalam keseluruhan aplikasi ini adalah warna campuran dari warna tradisional khas kain songket Palembang, yaitu warna merah (\#cc0000), kuning emas (\#cc9900), coklat muda (\#996633), hijau (\#006633) dan coklat tua (\#333300).

\section{Tipografi}

Konten teks pada aplikasi menggunakan fontset/Kelompok huruf Arabic Typesetting (regular) dan Utsaah (regular) dengan warna teks hitam. Fontset/Kelompok huruf yang digunakan untuk judul dan sub judul songket menggunakan font Freestyle Script (Bolt). Font ini dipilih karena font style 'berkait', sehingga sangat cocok untuk membentuk nuansa tradisioanal pada aplikasi.

\section{Sound Effect dan Musik}

Beberapa Sound effect yang digunakan pada saat objek di klik. Peneliti memilih sebuah lagu tradisional khas Palembang yaitu Instrumen lagu "Gending Sriwijaya" sebagai latar musik aplikasi, sehingga pengguna merasakan berada didalam galeri songket Palembang dengan sentuhan musik tradisional.

\section{Splash Screen}

Splash screen pada aplikasi ini merupakan symbol khas aplikasi seperti pada gambar 3 . Simbol ini diambil dari bentuk motif nago besaung atau nago bertarung. Motif nago besaung merupakan salah satu motif kain songket Palembang, motif nago besaung adalah motif inti atau motif utama dan lambang dari songket Palembang. Gambar dekoratif ini melukiskan sepasang atau dua naga yang saling berhadapan. Di antara kepala (mulut) kedua naga itu terdapat bola emas. Warna merah dan kuning emas dipilih, karena warna merah dan kuning emas merupakan warna khas songket Palembang pada masa perkembangan awal, yaitu dua warna utama tradisi Cina. Merah bermakna berani, sedangkan kuning (emas) bermakna kekayaan, kejayaan, dan kemakmuran.

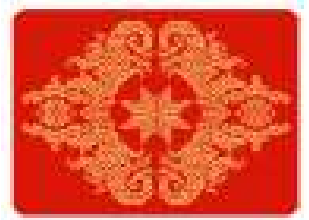

Gambar 3. Splash screen Aplikasi

\section{Tampilan Aplikasi}

Halaman utama aplikasi terdiri dari latar galeri songket yang menampilkan display motif-motif songket Palembang. Pada halaman utama seperti pada gambar 4 dibuat secara horizontal (kiri ke kanan), yaitu menggunakan konsep ruang galeri sebagai setting/latar utama aplikasi, sehingga pengguna merasakan seperti berada di dalam galeri songket yang di dalamnya terdapat koleksi ragam hias songket Palembang.

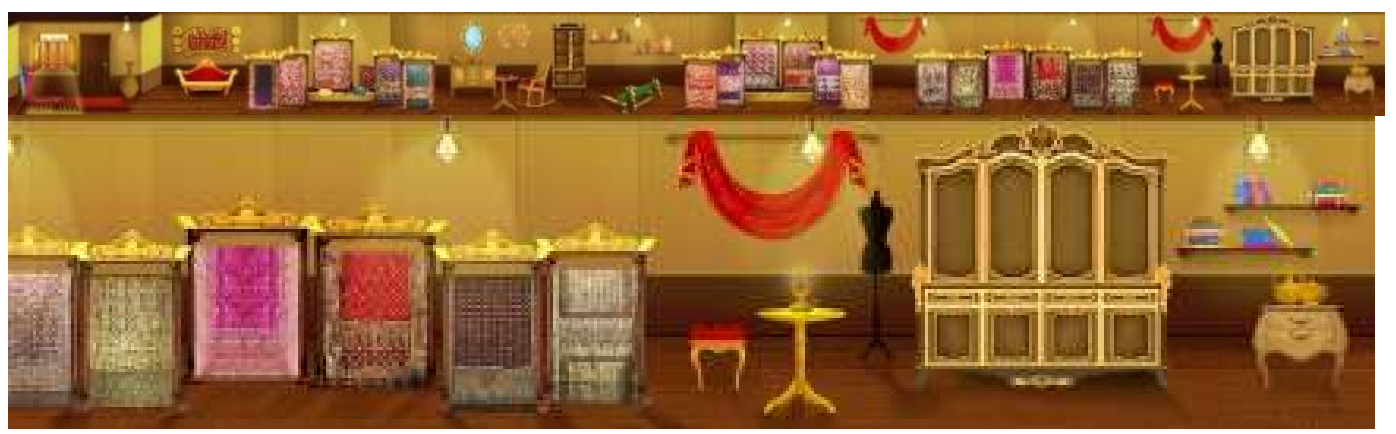

Gambar 4. Halaman Utama Aplikasi 
Pada gambar 5 navigasi halaman utama terdapat tampilan 17 motif lama yang dipajang di galeri songket. Pengguna dapat mengklik salah satu display songket, setelah itu akan mendapatkan informasi detail mengenai motif songket Palembang.

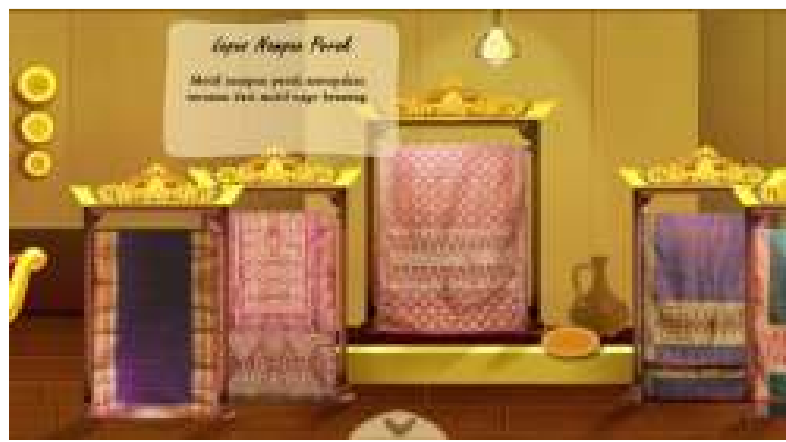

Gambar 5. Navigasi Halaman Utama Aplikasi

Setelah diklik beberapa kali pada papan deskripsi singkat, maka akan muncul pertanyaan kuis "Motif Apakah Ini?". Kuis ini berguna untuk memotivasi pengguna agar mengingat motif-motif yang ditampilkan di ruang galeri. Jika berhasil, maka pengguna akan memasuki halaman popup baru yang menginformasikan motif songket secara detail seperti pada gambar 6 .

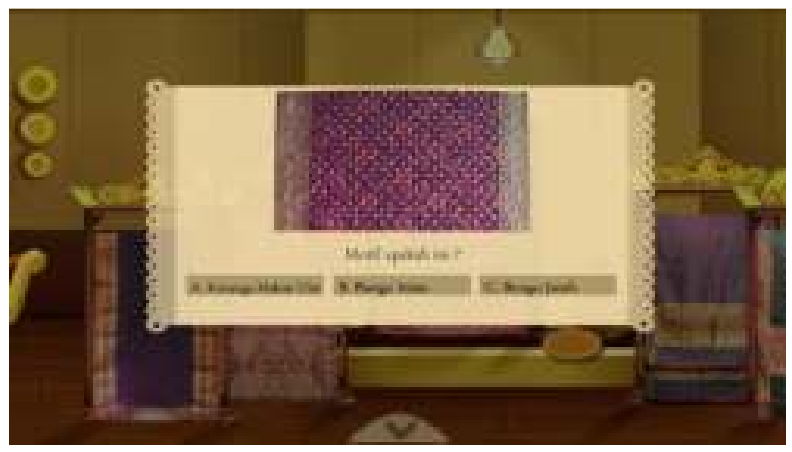

Gambar 6. Navigasi Kuis pada Halaman Utama Aplikasi

Pada halaman utama pengguna dapat mengklik tanda panah menu pada bagian bawah. Terdapat tujuh menu utama aplikasi, yaitu mini game, komposisi, pencarian, artikel, alat tenun, suara, dan informasi aplikasi seperti pada gambar 7 .

\section{1) Game Mini}

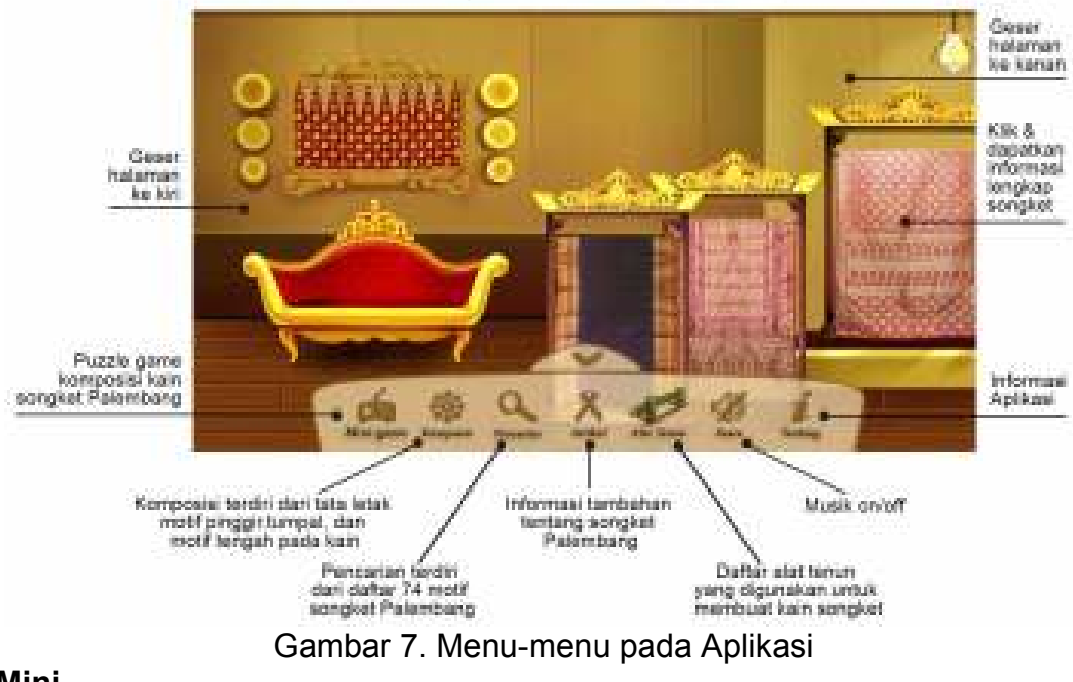


Menu mini game terdiri dari tiga kategori, yaitu lepus nago besaung, bungo pacik, dan lepus bintang beranti yang disesuaikan dengan nama motif songket Palembang. Pengguna diberi waktu 3 menit untuk menentukan tataletak komposisi/struktur motif songket dengan format drag \& drop. Pengguna juga dapat mewarnai kain motif sesuai keinginan dan meng-capture motif saat game selesai. Fitur mini game bertujuan agar pengguna cepat mengigat komposisi pada kain songket Palembang. Melihat dari kecendrungan siswa SMP yang telah mampu menalar secara logis dan menarik kesimpulan dari informasi yang tersedia, maka Fitur mini game akan membuat pengguna secara tidak langsung belajar dan mengingat komposisi kain songket seperti pada gambar 8 berikut.

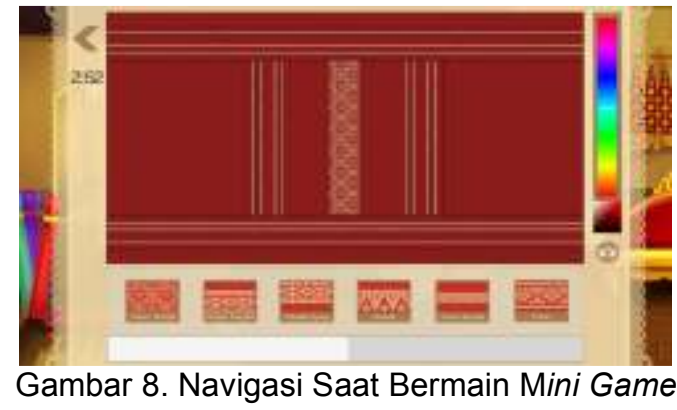

\section{2) Komposisi}

Menu komposisi memberikan informasi lengkap tentang komposisi/struktur kain songket Palembang, yang merupakan pakem dalam pembuatan kain songket. Pada menu komposisi terdiri dari tiga bagian utama, yaitu motif tengah, motif pinggir, dan motif tumpal. Ketika pengguna mengklik bagian motif pinggir, maka akan tampil seperti gambar 9. Saat pengguna mengklik bagian-bagian yang berbentuk lingkaran merah, maka akan tampil informasi detail tentang motif tersebut.

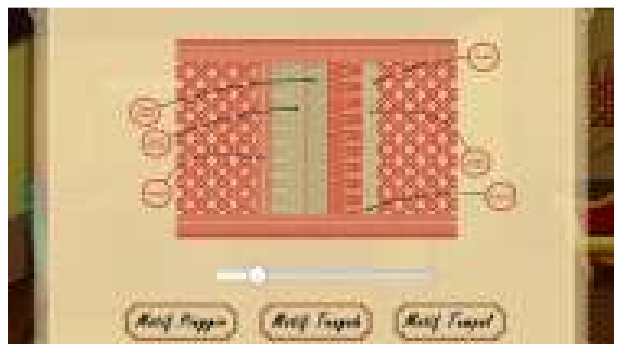

Gambar 9. Navigasi Motif Tumpal pada Menu Komposisi

\section{3) Menu Pencarian}

Menu pencarian memberikan informasi daftar 74 motif songket. Pengguna dapat mencari motif songket yang diinginkan berdasarkan pencarian 'nama' dan 'abjad' melalui button pencarian seperti gambar 10 .

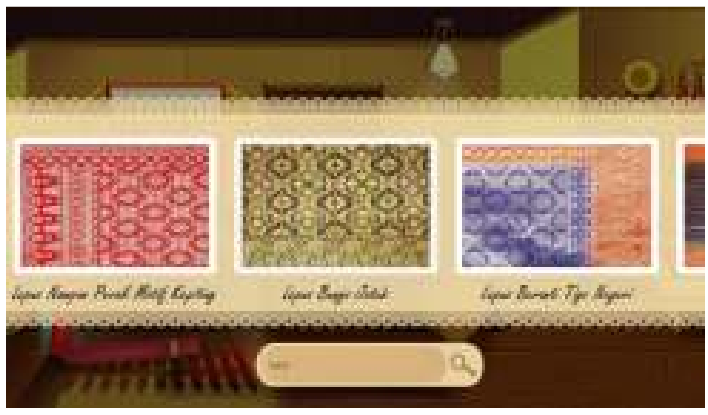

4) Menu Artikel

Gambar 10. Navigasi pada Menu Pencarian Motif Songket 
Menu artikel memberikan informasi yang berkaitan dengan songket Palembang. Informasi tersebut terdiri dari, sejarah songket, kegunaan, baju adat, kain tradisional, proses pembuatan, bahan-bahan pembuatan, dan lain-lain.

\section{5) Menu Alat Tenun}

Menu alat tenun memberikan informasi lengkap tentang alat-alat untuk proses menenun kain songket.

\subsection{Pengujian Aplikasi}

Peneliti melakukan Pengujian Aplikasi untuk mengetahui pengalaman pengguna terhadap aplikasi dan pengukuran keberhasilan aplikasi sebagai informasi pengetahuan dasar songket Palembang. Peneliti melakukan dua tahap penyebaran sample, yaitu pre-test, ujicoba dan posttest pada siswa-siswi SMP Labschool UPI Cibiru dengan jumlah 41 siswa $(\mathrm{n}=41)$. Adapun hasil dari ujicoba ini sebagai berikut.

Tabel. 1 Hasil Uji Coba Aplikasi

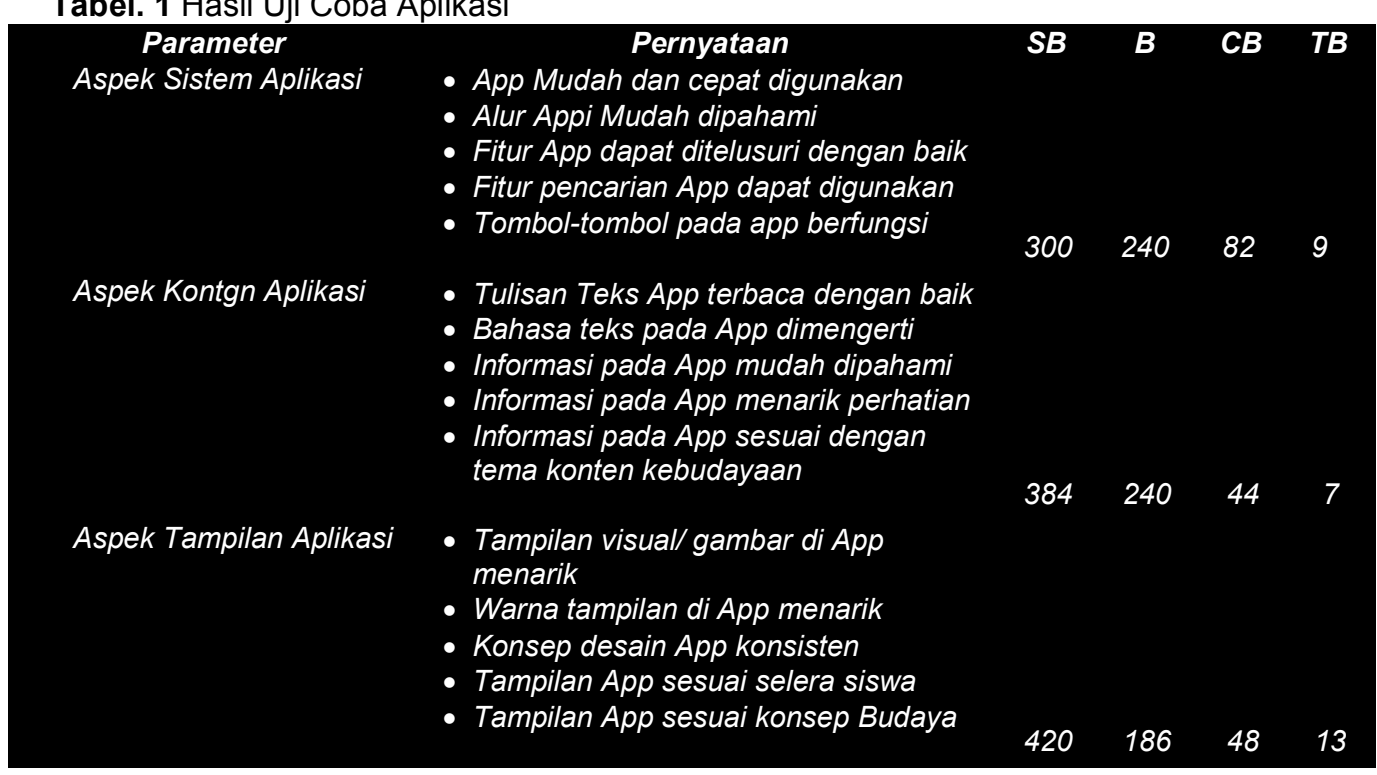

Berdasarkan Tabel 1 diatas. Grafik Validasi Aplikasi, peneliti dapat menyimpulkan menggunakan perhitungan rata-rata jawaban berdasarkan skoring setiap jawaban dari siswa. Jumlah skor ideal untuk seluruh item $=5$ (Point) $\times 41$ siswa $\times 4(\mathrm{SB})=820$.

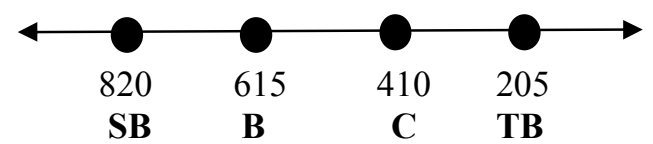

Pada Aspek Sistem Aplikasi, jumlah skor total yang diperoleh $=631$. Berdasarkan data tersebut maka $=(631: 820) \times 100 \%=77 \%$ dari yang diharapkan $(100 \%)$. Jadi rata-rata dari Aspek Sistem Aplikasi dengan skor 631 terletak di point "Baik".

Pada Aspek Konten Aplikasi, jumlah skor total yang diperoleh $=745$. Berdasarkan data tersebut maka $=(745: 820) \times 100 \%=90 \%$ dari yang diharapkan $(100 \%)$. Jadi rata-rata dari Aspek Konten Aplikasi dengan skor 745 terletak di point "Sangat Baik".

Pada Aspek Tampilan Aplikasi, jumlah skor total yang diperoleh $=667$. Berdasarkan data tersebut maka $=(667: 820) \times 100 \%=81 \%$ dari yang diharapkan $(100 \%)$. Jadi rata-rata dari Aspek Tampilan Aplikasi dengan skor 667 terletak di point "Baik". 


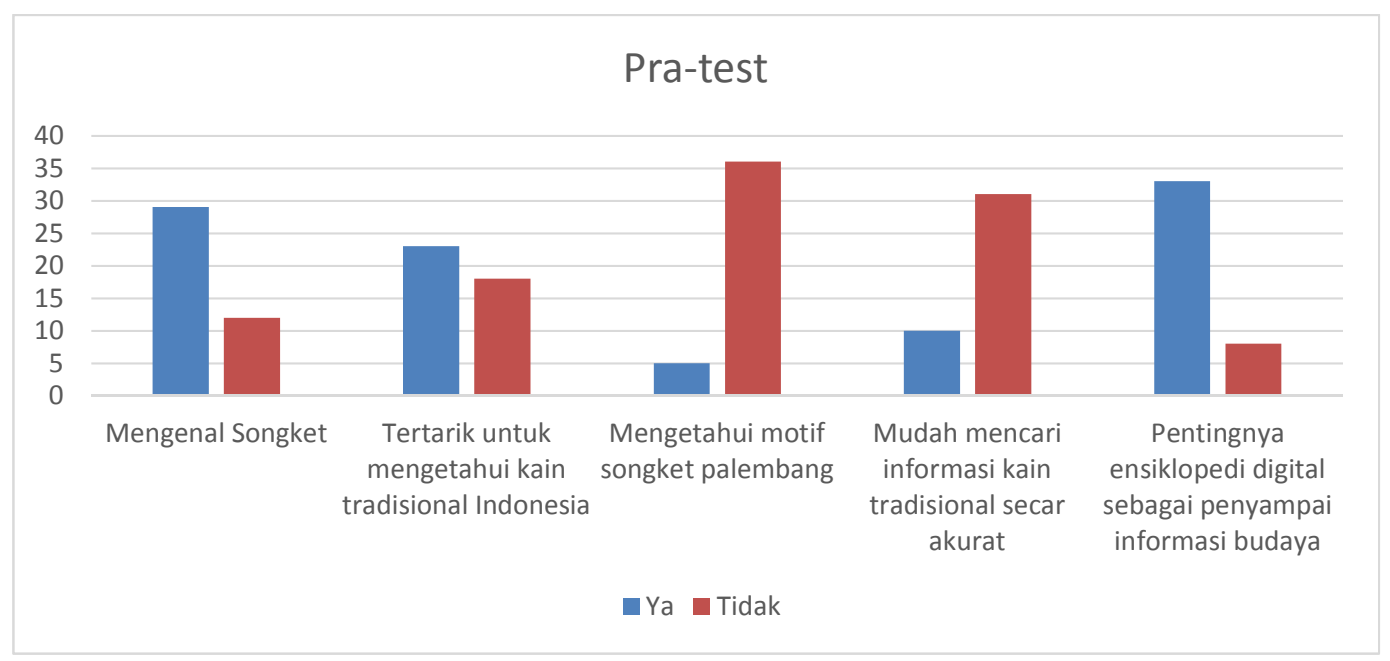

Gambar 11. Grafik Pre-test

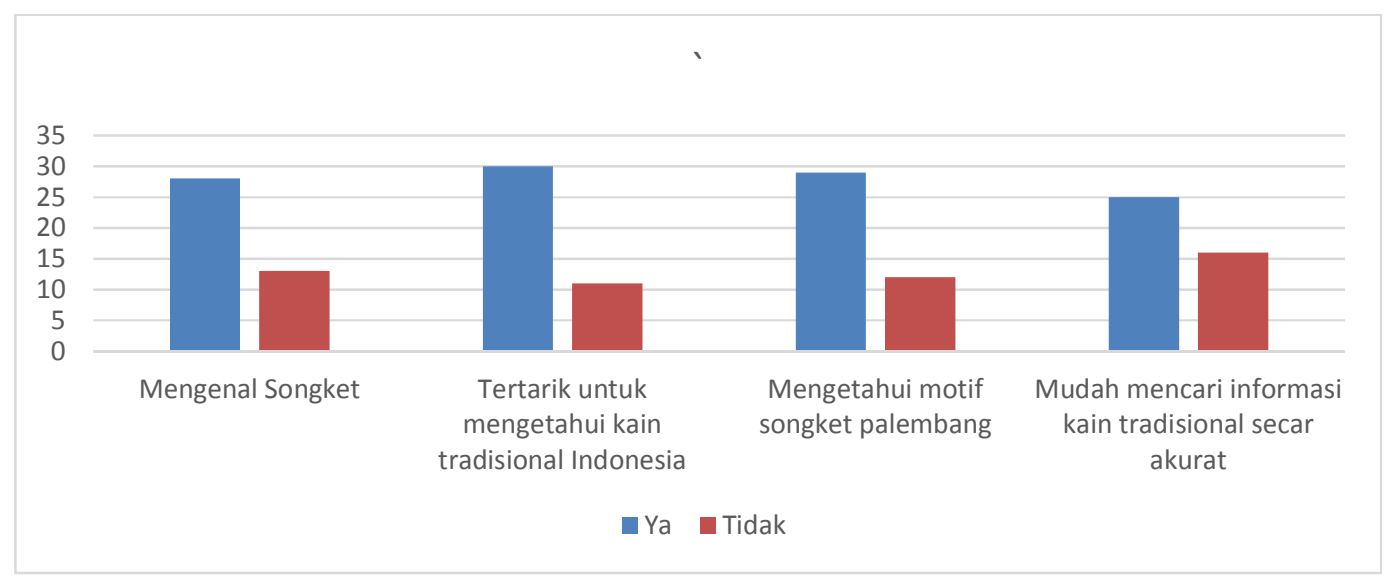

Gambar 12. Grafik Post-Test

Adapun hasil dari tahap pre-test dan post-test yang telah dilakukan pada gambar 11 dan gambar 12, dapat disimpulkan bawah pengetahuan remaja tentang informasi songket Palembang yang awalnya hanya $18 \%$ dari jumlah siswa yang tahu, meningkat menjadi $61 \%$ siswa setelah memainkan aplikasi ensiklopedia digital interaktif songket Palembang. Selain itu awalnya $56 \%$ siswa mulai tertarik untuk mengetahui kain tradisional, meningkat menjadi $73 \%$ siswa.

\section{Kesimpulan}

1. Penyajian Konten Informasi Budaya lokal Ragam Hias Songket Palembang untuk Siswa Jenjang SMP Palembang dirancang sederhana dan menarik tanpa mengorbankan kemudahan dan kejelasan, dengan menonjolkan visual 2D, effect animasi, serta penambahan fitur kuis dan mini game, sehingga dapat meningkatkan ketertarikan siswa untuk mengetahui informasi yang ada pada aplikasi.

2. Rancangan Aplikasi Ensiklopedia Digital Interaktif dibuat menggunakan Mobile Device dalam format Ensiklopedia Digital Interaktif Terbukti "Baik" sebagai media edukasi untuk memperkenalkan Ragam Hias Songket Palembang dan dapat meningkatkan pengetahuan dasar siswa tentang informasi budaya lokal. 


\section{Referensi}

[1] Megumi Uchino (2005) Socio-cultural history of Palembang Songket, Indonesia and the Malay World, 33:96, 205-223, DOI: 10.1080/13639810500283985

[2] Ernatip (BPSNT Padang), Inventarisasi Tenun Tradisional Songket palembang, no. April 2010. Jakarta: Direktorat Tradisi, Direktorat Jenderal Nilai Budaya, Seni dan Film, Kementerian Kebudayaan dan Pariwisata Jalan, 2010.

[3] Y. Syarofie, Songket Palembang: Nilai Filosofis, Jejak Sejarah, Dan Tradisi. Palembang: Dinas Pendidikan Provinsi Sumatera: Palembang, 2012.

[4] R. C. Jason Lankow, Josep Ritchie, Infografis : Kedasyatan Cara Bercerita Visual. Jakarta: Gramedia, 2014.

[5] Munir, MULTIMEDIA: Konsep \& Aplikasi dalam Pendidikan. Bandung: Alfabeta, 2012.

[6] Kominfo, "Survey Penggunaan TIK 2017 Serta Implikasinya Terhadap Aspek Sosial Budaya Masyarakat," pp. 1-58, 2017.

[7] N. Bima, Irfansyah, and Z. Alvanov, "Perancangan Ensiklopedia Digital Interaktif Tokoh Wayang Kulit Cirebon Pada Mobile Device," J. Komun. Vis. Multimed., vol. 5, no. 2, pp. 2340, 2013.

[8] E. Stolterman, "The nature of design practice and implications for interaction design research," Int. J. Des., vol. 2, no. 1, pp. 55-65, 2008.

[9] J. A. Abubakar, P. S. Jahnkassim, and M. Mahmud, "Effects of interactive digital media on architectural heritage learning," J. Teknol., vol. 78, no. 2-2, pp. 41-48, 2016.

[10] T. J. Ellis and Y. Levy, "A Guide for Novice Researchers: Design and Development Research Methods," Proc. 2010 InSITE Conf., no. December, pp. 107-118, 2010. 